\title{
White matter pathology - an endophenotype for bipolar disorder?
}

Stefan Borgwardt ${ }^{1,2,3^{*}}$ and Paolo Fusar-Poli ${ }^{2}$

\begin{abstract}
Background: Neuroimaging investigations of white matter abnormalities in subjects at genetic risk for bipolar disorders (BD) potentially predating the onset of BD offer several advantages. They are not confounded by the presence of illness duration or previous treatment with medication and may ultimately inform evaluation of risk for subsequent development of $\mathrm{BD}$ and subsequent therapeutic intervention.

Discussion: Although a number of imaging studies in subjects at genetic risk for BD are available the results are conflicting and no reliable structural markers of genetic liability to bipolar disorders have been proposed. We debate that white matter pathology may be central to the genetic risk to develop BD. Thus, white matter abnormalities detectable in HR subjects but not in controls may reflect genetically driven trait markers. Similar abnormalities may be also evident both in the $\mathrm{HR}$ and in $\mathrm{BD}$, suggesting the possibility of genetic risk factors shared by both groups. Conversely, white matter alterations observed in BD patients but not in HR and controls can be interpreted as state markers.
\end{abstract}

Summary: We suggest that white matter alterations may represent endophenotypes and neurobiological markers intermediate between the underlying susceptibility genes and the clinical expression of BD.

\section{Background}

A number of structural brain imaging studies and metaanalytic reviews have shown that white matter reductions are consistently found in bipolar disorder [1]. A meta-analysis of 98 structural imaging studies showed that bipolar disorder was associated with lateral ventricle enlargement and increased rates of deep white matter hyperintensities [2]. Moreover, in a recently published tract-specific diffusion-tensor imaging (DTI) study by Benedetti et al. it was shown that patients with BD had significantly decreased average fractional anisotropy (FA) and increased average mean diffusivity in the majority of the white matter (WM) fiber bundles [3].

\section{Discussion}

Neuroimaging investigations of structural and functional brain abnormalities in subjects at genetic risk for bipolar disorder (BD) offer several advantages. They are not confounded by illness duration or exposure to previous

\footnotetext{
* Correspondence: stefan.borgwardt@kcl.ac.uk

${ }^{1}$ Department of Psychiatry, University of Basel, Basel, Switzerland

${ }^{2}$ King's College, Institute of Psychiatry, King's College London, London, UK

Full list of author information is available at the end of the article
}

treatments and may ultimately inform evaluation of risk for subsequent development of $\mathrm{BD}$ and subsequent therapeutic intervention [4]. Although a number of imaging studies in subjects at high risk (HR) for BD are available, the results are conflicting and no reliable imaging markers of genetic liability to BD is clinically available yet [5-8].

In a recent systematic meta-analysis of neuroimaging studies of 996 HR subjects for BD and 1258 controls, we confirmed inconclusive structural findings but increased neurofunctional response during cognitive tasks in the prefrontal and temporo-insular regions [9]. On the basis of the study by Benedetti et al. [3] it is possible to speculate that temporo-limbic white matter (WM) alterations may alter the neurofunctional connectivity and ultimately the regional response during cognitive tasks. Specifically, region-of-interest magnetic resonance imaging (MRI) studies of twins found decreased left hemispheric WM volume in either BD patients or co-twins (HR) compared with control twin subjects [10]. This indicated that genes involved in the etiology of BD may contribute to the WM decreases found in BD patients and in their co-twins (HR) (trait markers) [11]. However, other MRI

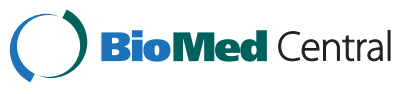


studies reported contrasting findings with no significant WM alterations in the HR as compared to controls $[12,13]$ or to BD [14]. Others suggested more circumscribed and limited WM alterations in the major tracts of the brain [15] in line with the findings of Benedetti et al. [3]. DTI studies in the HR group showed reduced FA in the superior longitudinal fasciculus as compared to controls [6] and FA in HR intermediate to controls and BD patients [16]. Significant reductions in the number, density, and size of glial cells could be reflected in reduced WM tissue and signal hyperintensities, which are often reported in HR subjects [6].

The genetics of bipolar disorder is complex and relatives are most likely to carry some risk allels [11], unaffected relatives of BD patients are likely to share some susceptibility genes with affected patients. We therefore suggest that WM alterations may represent endophenotypes and neurobiological markers intermediate between the underlying susceptibility genes and the clinical expression of BD. A recently published study of monozygotic and dizygotic twin pairs revealed segregating genetic liabilities specifically associated with thicker right parietal cortex in schizophrenia and larger intracranial volume for BD [7]. However, disruptions in WM integrity have been implicated as endophenotype in schizophrenia and evidence includes neuroimaging studies of first-episode and chronic patients that report WM volume reductions and structural abnormalities, as well as myelin-related gene abnormalities [17]. Overlapping WM alterations between these two HR groups raises the possibility that schizophrenia and bipolar disorders share common endophenotypes [18-21].

\section{Summary}

We suggested that white matter alterations may represent endophenotypes and neurobiological markers intermediate between the underlying susceptibility genes and the clinical expression of BD. Disturbed WM integrity in patients with BD will be better elucidated by imaging studies, investigating larger and more homogenous samples and employing longitudinal designs to dissect neurobiological abnormalities that are underlying traits of the illness from those related to psychopathological states such as episodes of mood exacerbation or pharmacological treatment. Moreover, there should be more direct comparisons between HR schizophrenia and HR BD groups. Similar to clinical [22,23], cognitive [24] and imaging [25-28] HR studies for schizophrenia, biomarkers of risk that differentiate those who will go on to develop BD from those that will not are needed. Additionally, future tractography studies following up genetic versus clinical $H R$ samples are required to elucidate these issues and eventually clarify the role played by WM alterations in the development of the diseases.

\section{Competing interests}

The authors declare that they have no competing interest.

\section{Authors' contribution}

SB and PFP drafted the manuscript. Both authors approved the final version.

\section{Authors' information}

Paolo Fusar-Poli is an Associate Professor at the Institute of Psychiatry, King's College, London, UK. Stefan Borgwardt is Professor of Neuropsychiatry at the University of Basel, Switzerland and Visiting Professor at the Institute of Psychiatry, King's College, London, UK.

\section{Author details}

${ }^{1}$ Department of Psychiatry, University of Basel, Basel, Switzerland. ${ }^{2}$ King's College, Institute of Psychiatry, King's College London, London, UK. ${ }^{3}$ Medical Image Analysis Centre, University of Basel, Basel, Switzerland.

Received: 11 July 2012 Accepted: 4 September 2012 Published: 13 September 2012

\section{References}

1. De Peri L, Crescini A, Deste G, Fusar-Poli P, Sacchetti E, Vita A: Brain structural abnormalities at the onset of schizophrenia and bipolar disorder: a meta-analysis of controlled magnetic resonance imaging studies. Curr Pharm Des 2012, 18(4):486-494.

2. Kempton MJ, Geddes JR, Ettinger U, Williams SC, Grasby PM: Meta-analysis, database, and meta-regression of 98 structural imaging studies in bipolar disorder. Arch Gen Psychiatry 2008, 65(9):1017-1032.

3. Benedetti F, Absinta M, Rocca MA, Radaelli D, Poletti S, Bernasconi A, Dallaspezia S, Pagani E, Falini A, Copetti M, et al: Tract-specific white matter structural disruption in patients with bipolar disorder. Bipolar Disord 2011, 13(4):414-424.

4. Fusar-Poli P, Howes O, Bechdolf A, Borgwardt S: Mapping vulnerability to bipolar disorder: a systematic review and meta-analysis of neuroimaging studies. Journal of psychiatry \& neuroscience: JPN 2012, 37(3):170-184.

5. Sprooten E, Sussmann JE, Clugston A, Peel A, McKirdy J, Moorhead TW, Anderson S, Shand AJ, Giles S, Bastin ME, et al: White matter integrity in individuals at high genetic risk of bipolar disorder. Biol Psychiatry 2011, 70(4):350-356.

6. Frazier JA, Breeze $J$, Papadimitriou G, Kennedy DN, Hodge SM, Moore CM, Howard JD, Rohan MP, Caviness VS, Makris N: White matter abnormalities in children with and at risk for bipolar disorder. Bipolar Disord 2007, 9(8):799-809.

7. Hulshoff Pol HE, van Baal GC, Schnack HG, Brans RG, van der Schot AC, Brouwer RM, van Haren NE, Lepage C, Collins DL, Evans AC, et al: Overlapping and segregating structural brain abnormalities in twins with schizophrenia or bipolar disorder. Arch Gen Psychiatry 2012, 69(4):349-359.

8. Borgwardt S, Radua J, Mechelli A, Fusar-Poli P: Why are psychiatric imaging methods clinically unreliable? Conclusions and practical guidelines for authors, editors and reviewers. Behav Brain Funct 2012, 8(1):46.

9. Fusar-Poli P, Howes OD, Allen P, Broome M, Valli I, Asselin MC, Montgomery AJ, Grasby PM, McGuire P: Abnormal prefrontal activation directly related to pre-synaptic striatal dopamine dysfunction in people at clinical high risk for psychosis. Mol Psychiatry 2011, 16(1):67-75.

10. Kieseppa T, van Erp TG, Haukka J, Partonen T, Cannon TD, Poutanen VP, Kaprio J, Lonnqvist J: Reduced left hemispheric white matter volume in twins with bipolar I disorder. Biol Psychiatry 2003, 54(9):896-905.

11. van der Schot AC, Vonk R, Brans RG, van Haren NE, Koolschijn PC, Nuboer V, Schnack HG, van Baal GC, Boomsma DI, Nolen WA, et al: Influence of genes and environment on brain volumes in twin pairs concordant and discordant for bipolar disorder. Arch Gen Psychiatry 2009, 66(2):142-151.

12. Mclntosh AM, Job DE, Moorhead TW, Harrison LK, Lawrie SM, Johnstone EC: White matter density in patients with schizophrenia, bipolar disorder and their unaffected relatives. Biol Psychiatry 2005, 58(3):254-257.

13. Walterfang M, Wood AG, Barton S, Velakoulis D, Chen J, Reutens DC, Kempton MJ, Haldane M, Pantelis C, Frangou S: Corpus callosum size and shape alterations in individuals with bipolar disorder and their firstdegree relatives. Prog Neuropsychopharmacol Biol Psychiatry 2009, 33(6):1050-1057.

14. Forcada I, Papachristou E, Mur M, Christodoulou T, Jogia J, Reichenberg A, Vieta E, Frangou S: The impact of general intellectual ability and white 
matter volume on the functional outcome of patients with Bipolar Disorder and their relatives. J Affect Disord 2010, 130(3):413-420.

15. van der Schot AC, Vonk R, Brouwer RM, van Baal GC, Brans RG, van Haren $\mathrm{NE}$, Schnack HG, Boomsma DI, Nolen WA, Hulshoff Pol HE, et al: Genetic and environmental influences on focal brain density in bipolar disorder. Brain 2010, 133(10):3080-3092.

16. Chaddock CA, Barker GJ, Marshall N, Schulze K, Hall MH, Fern A, Walshe M,

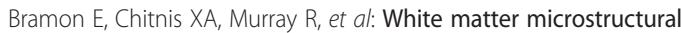
impairments and genetic liability to familial bipolar I disorder. Br J Psychiatry 2009, 194(6):527-534.

17. Karlsgodt KH, Niendam TA, Bearden CE, Cannon TD: White matter integrity and prediction of social and role functioning in subjects at ultra-high risk for psychosis. Biol Psychiatry 2009, 66(6):562-569.

18. Francks C, Tozzi F, Farmer A, Vincent JB, Rujescu D, St Clair D, Muglia P: Population-based linkage analysis of schizophrenia and bipolar case-control cohorts identifies a potential susceptibility locus on 19q13. Mol Psychiatry 2010, 15(3):319-325.

19. Cichon S, Craddock N, Daly M, Faraone SV, Gejman PV, Kelsoe J, Lehner T, Levinson DF, Moran A, Sklar P, et al: Genomewide association studies: history, rationale, and prospects for psychiatric disorders. Am J Psychiatry 2009, 166(5):540-556.

20. Nyegaard M, Severinsen JE, Als TD, Hedemand A, Straarup S, Nordentoft M, McQuillin A, Bass N, Lawrence J, Thirumalai S, et al: Support of association between BRD1 and both schizophrenia and bipolar affective disorder. American journal of medical genetics Part B, Neuropsychiatric genetics: the official publication of the International Society of Psychiatric Genetics 2010, 153B(2):582-591

21. Lee KW, Woon PS, Teo YY, Sim K: Genome wide association studies (GWAS) and copy number variation (CNV) studies of the major psychoses: what have we learnt? Neurosci Biobehav Rev 2012, 36(1):556-571

22. Fusar-Poli P, Bonoldi I, Yung AR, Borgwardt S, Kempton MJ, Valmaggia L, Barale F, Caverzasi E, McGuire P: Predicting psychosis: meta-analysis of transition outcomes in individuals at high clinical risk. Arch Gen Psychiatry 2012, 69(3):220-229.

23. Fusar-Poli P, Borgwardt S: Predictive power of attenuated psychosis syndrome: is it really low? The case of mild cognitive impairment. Schizophr Res 2012, 135(1-3):192-193.

24. Fusar-Poli P, Deste G, Smieskova R, Barlati S, Yung AR, Howes O, Stieglitz RD, Vita A, McGuire P, Borgwardt S: Cognitive functioning in prodromal psychosis: a meta-analysiscognitive functioning in prodromal psychosis. Arch Gen Psychiatry 2012, 69(6):562-571.

25. Fusar-Poli P, Radua J, McGuire P, Borgwardt S: Neuroanatomical Maps of Psychosis Onset: Voxel-wise Meta-Analysis of Antipsychotic-Naive VBM Studies. Schizophr Bull 2011, Nov. 17 [Epub ahead of print].

26. Borgwardt S, Fusar-Poli P: Third-generation neuroimaging in early schizophrenia: translating research evidence into clinical utility. Br J Psychiatry 2012, 200(4):270-272

27. Fusar-Poli P, Smieskova R, Serafini G, Politi P, Borgwardt S: Neuroanatomical markers of genetic liability to psychosis and first episode psychosis: A voxelwise meta-analytical comparison. World J Biol Psychiatry 2012, Jan 27.

28. Smieskova R, Fusar-Poli P, Aston J, Simon A, Bendfeldt K, Lenz C, Stieglitz RD, McGuire P, Riecher-Rössler A, Borgwardt SJ: Insular volume abnormalities associated with different transition probabilities to psychosis. Psychol Med 2012, 42(8):1613-1625.

doi:10.1186/1471-244X-12-138

Cite this article as: Borgwardt and Fusar-Poli: White matter pathology an endophenotype for bipolar disorder? BMC Psychiatry 2012 12:138.

\section{Submit your next manuscript to BioMed Central and take full advantage of:}

- Convenient online submission

- Thorough peer review

- No space constraints or color figure charges

- Immediate publication on acceptance

- Inclusion in PubMed, CAS, Scopus and Google Scholar

- Research which is freely available for redistribution

Submit your manuscript at www.biomedcentral.com/submit
Biomed Central 